\title{
A NEWAPPROACH TOWARDS IMAGE BASED VIRTUAL 3D CITY MODELING BY USING CLOSE RANGE PHOTOGRAMMETRY
}

\author{
Surendra Pal Singh $^{1 a^{*}}$, Kamal Jain ${ }^{1 b}$, V. Ravibabu Mandla ${ }^{2}$ \\ ${ }^{1 \mathrm{a}}$ Geomatics Engineering Section, Department of Civil Engineering, Indian Institute of Technology, Roorkee, \\ (Roorkee), India. Corresponding author ${ }^{1{ }^{*}}$ Email- (surendra.geomatics@ gmail.com), \\ ${ }^{1 b}$ Geomatics Engineering Section, Department of Civil Engineering, Indian Institute of Technology, Roorkee, \\ (Roorkee), India. ${ }^{1 b}$ E-mail (kjainfce@iitr.ernet.in) \\ ${ }^{2}$ School of Mechanical and Building Sciences, Vellore Institute of Technology(VIT)-University,Vellore, Tamilnadu, \\ India. ${ }^{2}$ E-mail (ravi.mandla@ vit.ac.in)
}

\section{ISPRS Technical Commission V Symposium}

KEY WORDS: Virtual 3D city model, Geomatics techniques, Close Range Photogrammetry, Structure from Motion.

\section{ABSTRACT:}

3D city model is a digital representation of the Earth's surface and it's related objects such as building, tree, vegetation, and some manmade feature belonging to urban area. The demand of 3D city modeling is increasing day to day for various engineering and non-engineering applications. Generally three main image based approaches are using for virtual 3D city models generation. In first approach, researchers used Sketch based modeling, second method is Procedural grammar based modeling and third approach is Close range photogrammetry based modeling. Literature study shows that till date, there is no complete solution available to create complete 3D city model by using images. These image based methods also have limitations

This paper gives a new approach towards image based virtual 3D city modeling by using close range photogrammetry. This approach is divided into three sections. First, data acquisition process, second is 3D data processing, and third is data combination process. In data acquisition process, a multi-camera setup developed and used for video recording of an area. Image frames created from video data. Minimum required and suitable video image frame selected for 3D processing. In second section, based on close range photogrammetric principles and computer vision techniques, 3D model of area created. In third section, this 3D model exported to adding and merging of other pieces of large area. Scaling and alignment of 3D model was done. After applying the texturing and rendering on this model, a final photo-realistic textured 3D model created. This 3D model transferred into walk-through model or in movie form. Most of the processing steps are automatic. So this method is cost effective and less laborious. Accuracy of this model is good. For this research work, study area is the campus of department of civil engineering, Indian Institute of Technology, Roorkee. This campus acts as a prototype for city. Aerial photography is restricted in many country and high resolution satellite images are costly. In this study, proposed method is based on only simple video recording of area. Thus this proposed method is suitable for 3D city modeling.

Photo-realistic, scalable, geo-referenced virtual 3D city model is useful for various kinds of applications such as for planning in navigation, tourism, disasters management, transportations, municipality, urban and environmental managements, real-estate industry. Thus this study will provide a good roadmap for geomatics community to create photo-realistic virtual 3D city model by using close range photogrammetry.

\section{INTRODUCTION}

At present scenario, there are three main image based techniques used to create virtual 3D city model. One is sketch based method, second is procedural based method and third is close range photogrammetry based method.

Sketch based modeling is simple and not fulfill the engineering requirements (Singh et al., 2013 b). Procedural based modeling is also not easy for normal user (Singh et al., 2014). Close range based method is not suitable for large landscape modeling (Singh et al., 2013 d). Previous available research literature shows that each and every method has some advantages and also has some limitations. Previous study shows that, till date, there is no perfect solution available to create complete 3D city model. Thus a system \& method is required to create $3 \mathrm{D}$ city model in efficient way.
The main aim of this research is to develop an image based method for 3D city modeling. For any close range photogrammetric project, image acquisition is an important work. Image acquisition needs lot of experience. During photography, overlapping in images is necessary. Some time suitable position of camera is not easily obtained due to complex nature of project site. Thus, to solve this problem, multi-camera setup designed for video recording of large area. Video recording is easy and cost effective for image acquisition. Large area can be captured in less time by a single person. From this video data, image frames created by video to image frames converter software. Suitable image frames segregated and by using these image frames, 3D model of an area created (Singh et al., 2014 a). 
The previous study (Singh et al., 2012, Singh et al., 2013d) also shows that digital camera images are good source to obtained effective virtual 3D campus of any institute. A good collection of literature can be found on image based 3D city modeling techniques and applications (Singh et al., 2013c), Image based 3D modeling: a review (Remondino, Fabio, and Sabry El-Hakim., 2006), an update on automatic 3D building reconstruction (Hala and Kada 2010) and underwater stereoimage measurement for marine biology and ecological applications (Shortis et al., (2009).

From aerial stereo-photos, 3D campus was created for University of Technology, Malaysia (UTM), by using 3D digitization with photogrammetric concept (Anuar and Lawali, 2011).

Close range photogrammetry (CRP) is also a good option to create virtual 3D campus model (Singh et al., 2012, Singh et al., 2013d), but camera calibration, experience photography, roof texture, complex mathematical modeling and problem to find suitable position for photographs are the main weakness in close range photogrammetric work.

The importance of digital camera for 3D building modeling was discussed by Shashi and Jain, 2007. A multi-camera setup was designed and also developed a method for multi camera calibration for fast data acquisition in image based 3D modeling work. It was a better approach for digital image data acquisition for 3D city modeling. (Singh et al., 2013a)

A sketch based modeling was also studied and discussed by Singh et al., 2013b, and SketchUp software was used in their work to create 3D campus of department of civil engineering, IIT-Roorkee, India. It was low cost and simple solution for image based 3D campus modeling but, it was not advance 3D model and has some limitations.

iCampus project was completed for virtual 3D campus model of York University (C. Armenakis and G.Sohn, 2009). In this work, airborne and terrestrial images were used with lidar data. 3D campus modeling was done by using laser scanner data (Zulkepli et al., 2008)

Goel and team of Dr Lohani from IIT-Kanpur were also developed an indigenous solution for 3D modeling. This system was based on laser scanning and suitable for 3D modeling. They provide this system as low cost mobile mapping system for 3D scene reconstruction by using laser scanning approach (Goel et al., 2013).

Robson and Shortis (2007) explains about 3D measurement from images; mainly applications in engineering and manufacturing.

Shortis and Beyer (2001) explained about sensor technology for close range photogrammetry and machine vision.

Pottler et al., (2005) studied about photogrammetry as a powerful tool for geometric analysis of solar concentrators and their components.

Hosseininaveh et al., (2013) discussed about the comparison of dense matching algorithms for scaled surface reconstruction using stereo camera rigs.

Robson et al., (2013) explained about image selection in photogrammetric multi-view stereo methods for metric and complete $3 \mathrm{D}$ reconstruction.
David et al., (2001), discussed about laser scanning and photogrammetry as 21 st century metrology and F.Nex and F. Rinaudo (2011), explored about the reliability and potentiality of integration of lidar and photogrammetry.

F. Remondino et al., (2013), explained about the current status and future perspective of UAV Photogrammetry.

Based on literature, till now, there is no suitable method available to create $3 \mathrm{D}$ city model by using close range photogrammetric principles.

In this paper, a new image based photogrammetric method proposed for virtual 3D city modeling. This method is divided into three sections, one section explaining about the image data acquisition. In this section, a video based data acquisition system proposed. After video recording of an area, image frames created from video data. Second section is explaining about image frames 3D data processing methodology to create 3D model. In third section, a 3D model combination system proposed. Thus at last, a measurable, scalable, photo-realistic 3D model of an area created.

Accuracy of 3D model is depends on input measured value. The accuracy of 3D model is acceptable for this study. At the last sections, some advantages and limitations are also discussed.

\section{STUDY AREA}

Study area is department of civil engineering, Indian Institute of Technology, Roorkee, (IIT-R), Uttarakhand, India. The civil engineering department (CED) surrounded by department of earth science, department of architecture, department of water resources development and management (WRD\&M). This civil engineering department has the following main sections and buildings: Geomatics section building, Geotechnical section building (having CAD Lab and research scholar wing), Lecture hall building (having Newton rooms and Rayleigh rooms), Wind engineering section, O.P. Jain auditorium building, Transportation building, Main civil building, and Hydraulics building. (See figure 1.)

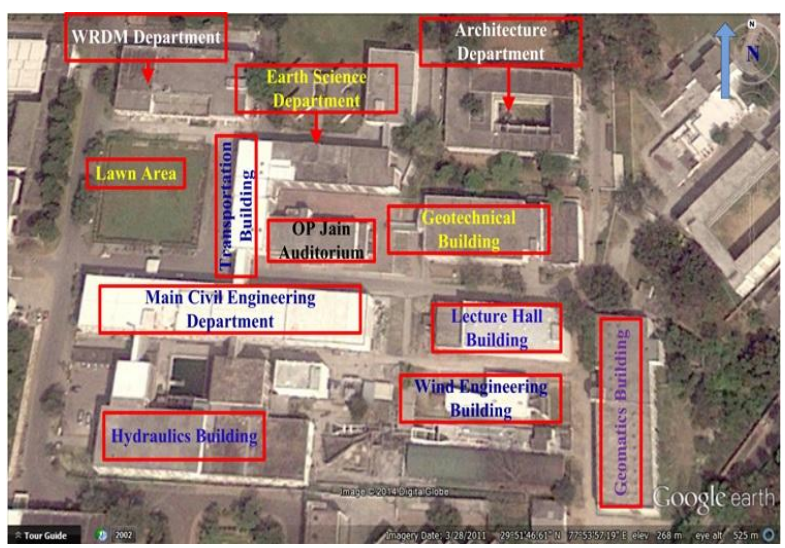

Figure 1: Department of Civil Engineering, IIT-Roorkee, (Uttarakhand), India (Source: Google Earth, January 2014) 


\section{METHODOLOGY}

The overall methodology is divided into three sections.
A- Method for data acquisition process
B- Method for 3D data processing
C- Method for data combination process

\section{A. Methodology for data acquisition process}

Image acquisition is a fundamental process for this work. Image based 3D city modeling is a process in which information about a city is extracted from sequence of images. For a large area, only video recording of a city gives better economical solution. A multi-camera setup is designed and developed for video recording of large area (Singh et.al 2013a).

Figure 2, showing the flow diagram of methodology for data acquisition.

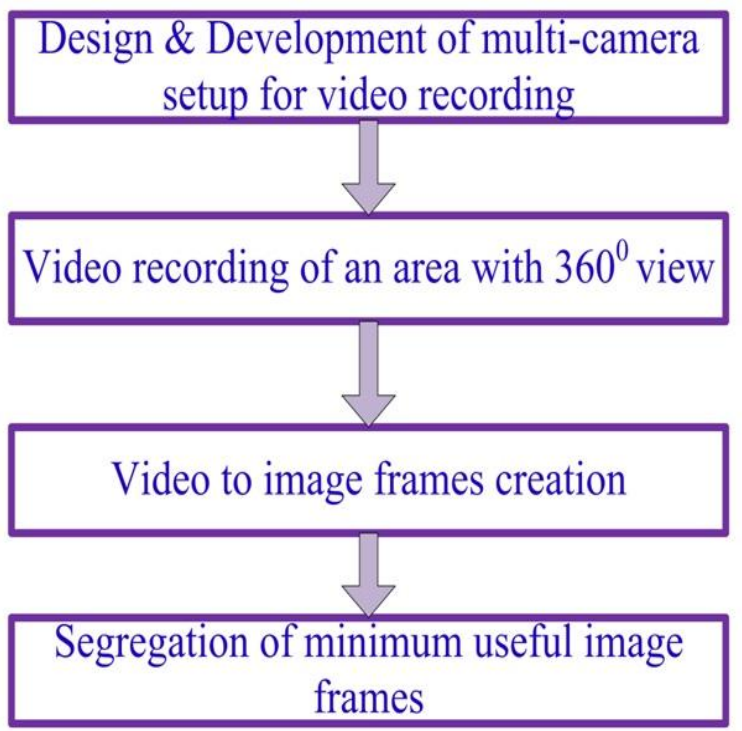

Figure 2: Flow diagram of methodology for data acquisition process

Video recording gives video image sequence. Video image sequence is a good image data source for 3D city modeling. Following are the main advantages of video image sequence:
a) It is economically suitable and flexible for image data acquisition.
b) The image data acquisition process is simple.
c) Less skilled person required.
d) Less changes in image.
e) More overlapping between the images.

Video recording of building at civil engineering department (CED) was done using multi camera set up. Video recording should be taken with slow moving speed in parallel direction for façade modeling. Weather conditions should be favorable during video recording. In this research work, the Sony DSC HX 7V digital camera was used for video recording. The Sony DSC HX7V digital camera is 16.2 mega pixel resolutions for image with focal length $4.6 \mathrm{~mm}$ and has Exmor R CMOS Image sensor. It has 10x optical zoom. This digital camera has record full HD video at $1920 \times 1080$ resolution. It has capacity to create 50 frames per second (FPS).

\section{Video image frame creation}

After video recording a scène, the video frames were created. Video camera has the feature "frames per second" (FPS) or "Frame rate". It is the characteristic feature of any video camera. It defines the frequency (or rate) at which the camera device produces unique consecutive images called frames. In this work, free software "Free video to JPG converter" was used. This software has the capacity to control the frame rate. It means, if video recording time is 5 minutes, $(5 \times 60=300$ seconds) and camera has 50 FPS. So in five minutes video $(300 \times 50=15000), 15000$ images frames were created. By using this software, one can change the frame rate. According to user requirements, one can choose every $10,30,50,100$, 500,1000 frames, or in every $1,2,5,10,20$ seconds. One can also choose total number of frames as 10, 20, 50,100,200,500, or can also extract every frame from video.

Figure 3, is showing some video image frames created by this software.

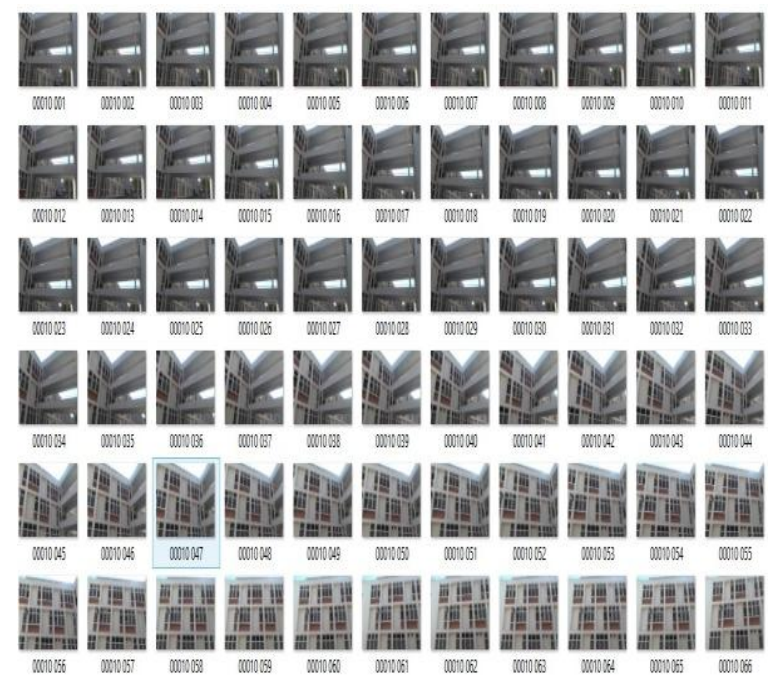

Figure 3: Some video image frames created from video

\section{Segregation of minimum useful image frames}

After extraction of video image frames, the minimum useful image frames for 3D image modeling were selected. One can use all created image frames, but computer system will heavy loaded during processing and create problem during image frames processing. Consecutive images or frames have more overlapping area. Therefore images frames after some interval were selected and it depends on overlapping area in image frames.

During segregation of image frames, following points are useful;

a) Image frames should be select in sequence.

b) It should be blurred free.

c) Sufficient overlapped area is necessary.

d) Minimum suitable frames should be used in $3 \mathrm{D}$ processing.

In such a way, minimum suitable image frames selected. These image frames are now useful for further 3D image processing. 


\section{B. Methodology for 3D data processing}

After data acquisition, the next step is image 3D data processing. Figure 4, is showing the overall methodology for $3 \mathrm{D}$ processing of image frames.

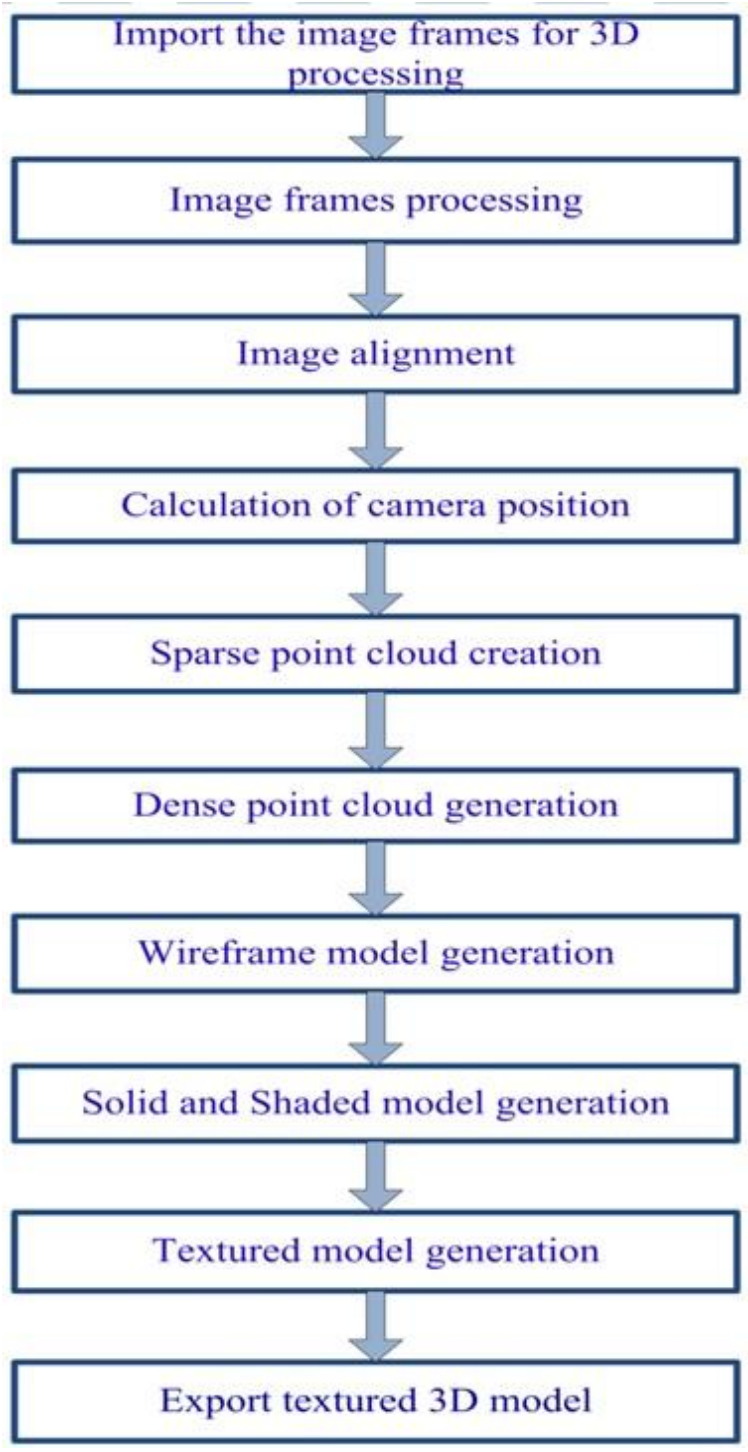

Figure 4: Flow diagram of methodology for 3D data processing

\section{Image frames processing}

These image frames were used for 3D model generation,. After processing of these video image frames, 3D points and model was obtained. Image alignment is an important function during processing for this work.

\section{Calculation of camera position}

After image alignment, camera position obtained for each video image frame. Fundamental matrix $(3 \times 3$ matrix, which relates the corresponding points in stereo images) was used and the intrinsic parameters of camera were calculated. After that, a solution for camera position was obtained. (R. Hartley 1992) (R. Hartley and A. Zisserman, 2003).
Figure 5, is showing the position of video image frames.

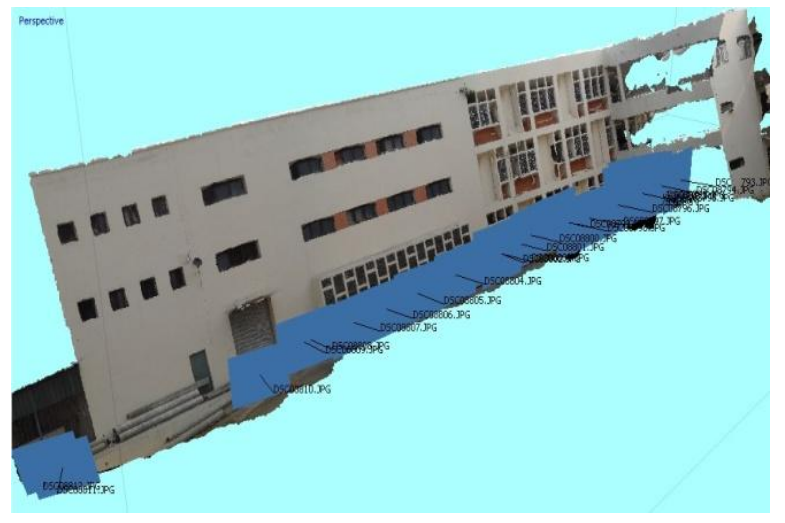

Figure 5: Building façade with video frame positions

\section{Sparse point cloud generation}

In this processing step, 3D point clouds were created by using Structure from Motion (SfM) techniques. Feature detection and feature matching were the key concepts to produce sparse 3D point cloud from image sequence (Noah Snavely et al., 2006). Figure 6, is showing the sparse point cloud model of an area from civil engineering department of IIT-Roorkee.

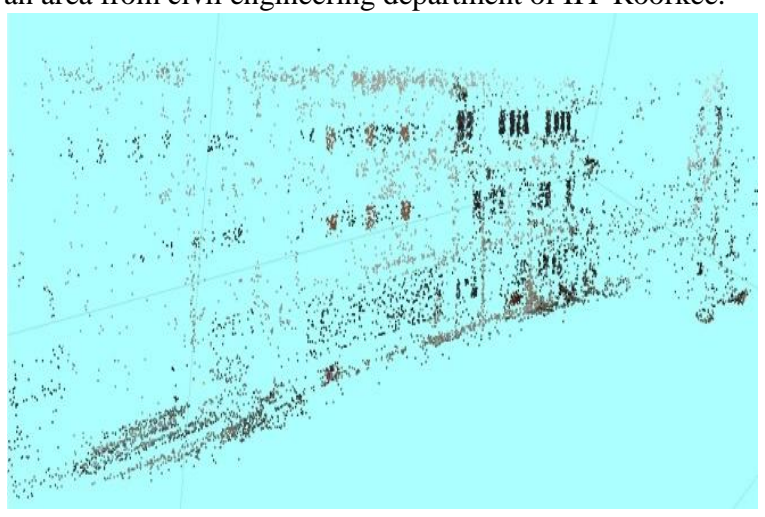

Figure 6: Sparse point cloud model

\section{Dense point cloud generation}

The number of point cloud increased using more efficient methods of feature matching techniques and dense point cloud models of an area were created. It produces more details of area. Figure 7, showing the dense point cloud model of area.

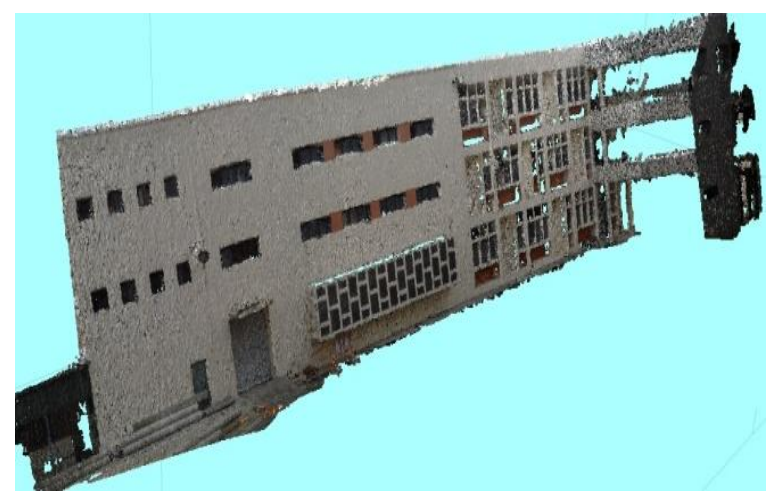

Figure 7: Dense point cloud model 


\section{Wireframe model generation}

Wireframe model also created with the help of these 3D points. Wireframe model is useful to produce exploded and perspective view more easily. This model is also useful for viewing the model from any desired point by changing line of sight. Figure 8, showing the wireframe model of an area.

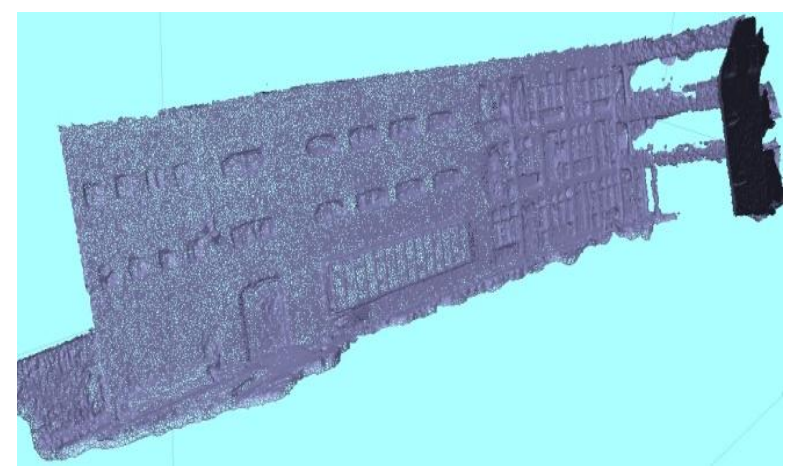

Figure 8: Wireframe model

\section{Solid and shaded model generation}

Wireframe model does not represent an actual solid and has no surface \& volume information. Thus, solid model and shaded surface model created. Solids model is a complete and unambiguous representation of a precisely enclosed and filled volume. Shaded model gives near about actual model of an area. Figure 9, and Figure 10, is showing the solid model and shaded model.

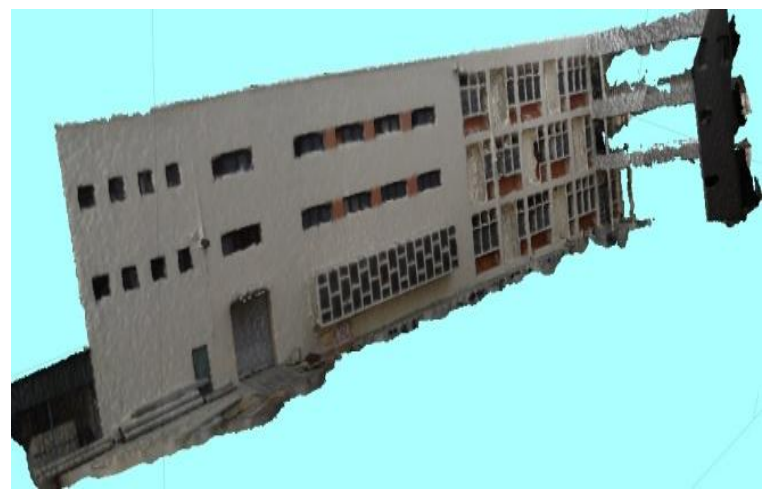

Figure 9: Solid model generation

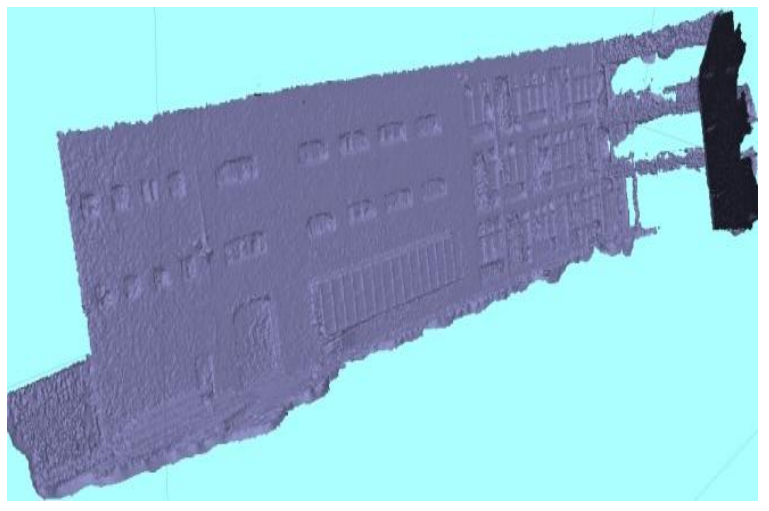

Figure 10: Shaded model generation

\section{Textured model generation}

At finally, generic texture method applied, which allows parameterization of texture atlas for arbitrary geometry and make final textured 3D model of an area. It gives photorealistic representation of a scene.

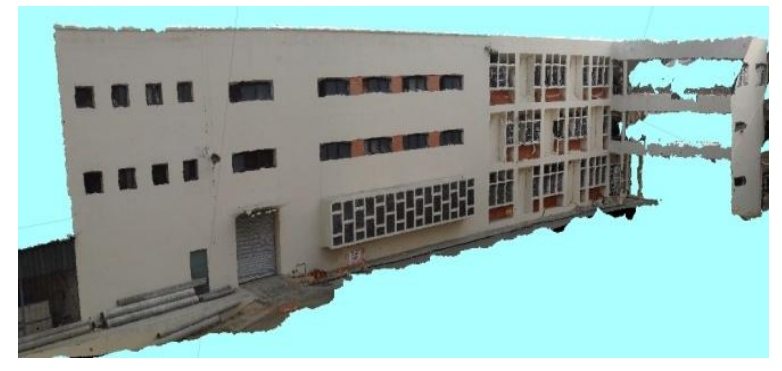

Figure 11: Textured 3D model of building of civil ngineering department

Thus, in this way, the other building sections were created. (See Figure 11, Fig.12, Fig.13, Fig.14, Fig.15 and Fig. 16)

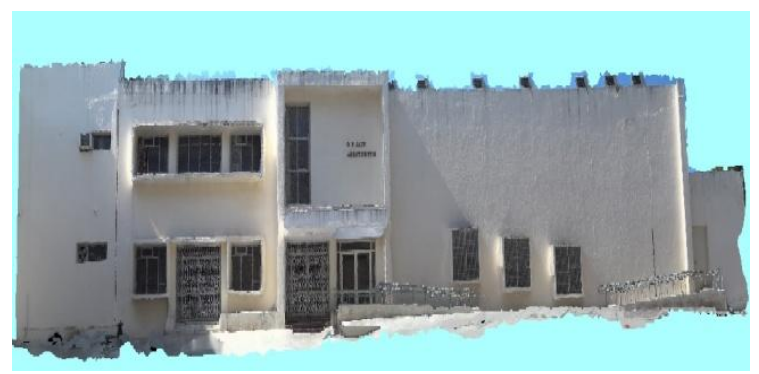

Figure 12: Textured 3D model of O.P.Jain auditorium building of civil engineering department

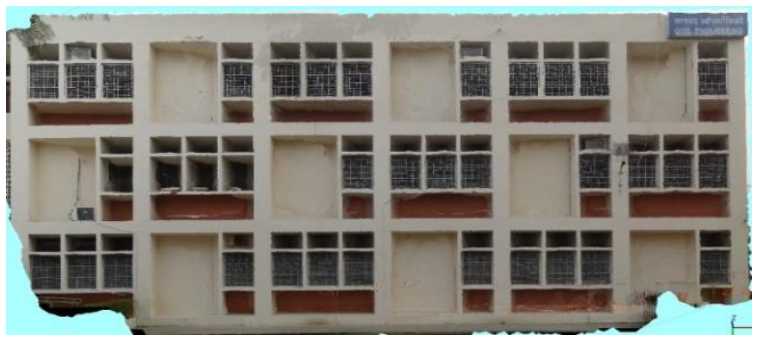

Figure 13: Textured façade model of main building of civil engineering department

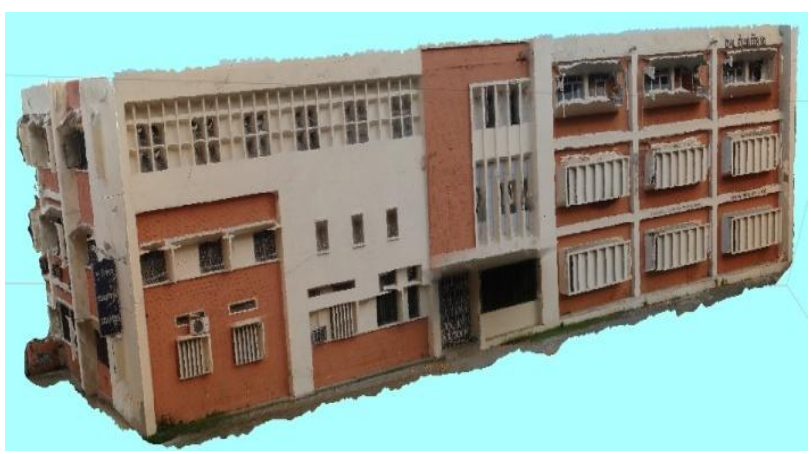

Figure 14: Textured 3D model of transportation section at civil engineering department 


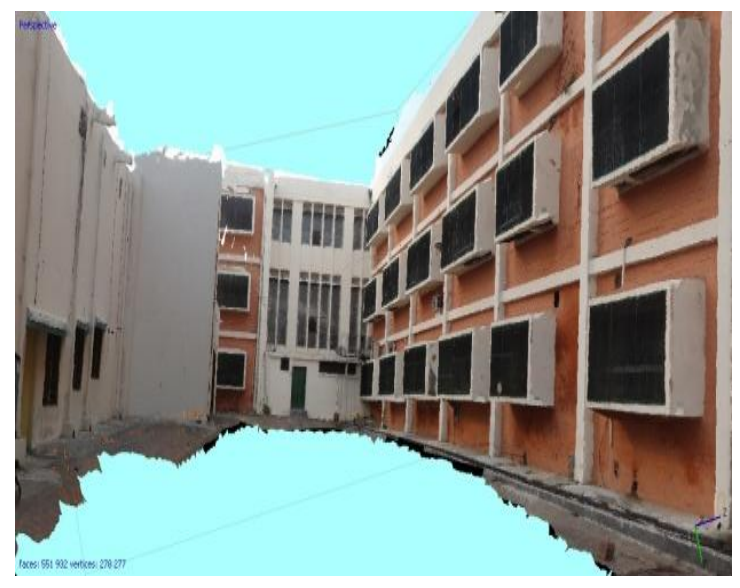

Figure 15: Textured 3D model of one portion of building at civil engineering department

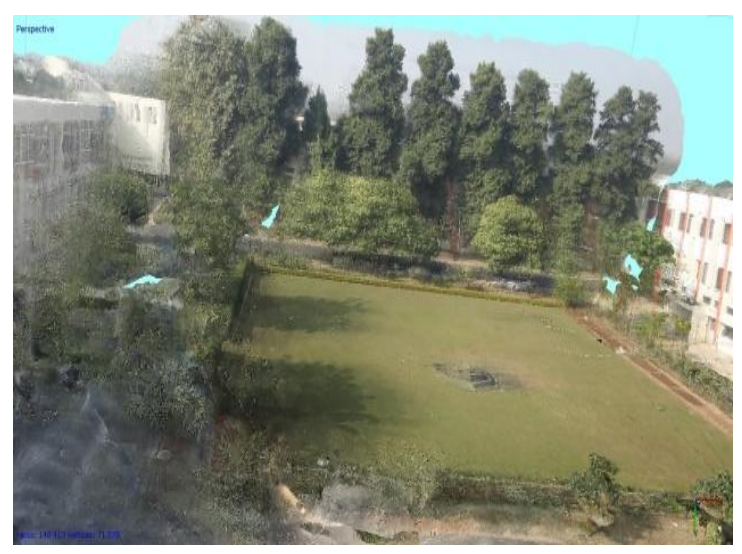

Figure 16: Textured 3D model of Lawn area (park) at civil engineering department

In such a way, all buildings of civil engineering department were created. These parts were exported to further next 3D data combination process.

Agisoft Photoscan Pro software (Web-reference 1) was used in this section for 3D data processing. Agisoft Photoscan software works mainly on computer vision based techniques. Structure from Motion (SfM), and multi-view reconstruction techniques are main principles on which Agisoft create 3D model of an object. In this software, both image alignment and 3D model reconstruction are fully automated.

From this software, these 3D models exported in various formats for further processing.

\section{Methodology for data combination}

3Ds Max 2014, software (Web-reference 2) was used in this section for data combination process. Figure 17, showing the complete methodology for data combination process.

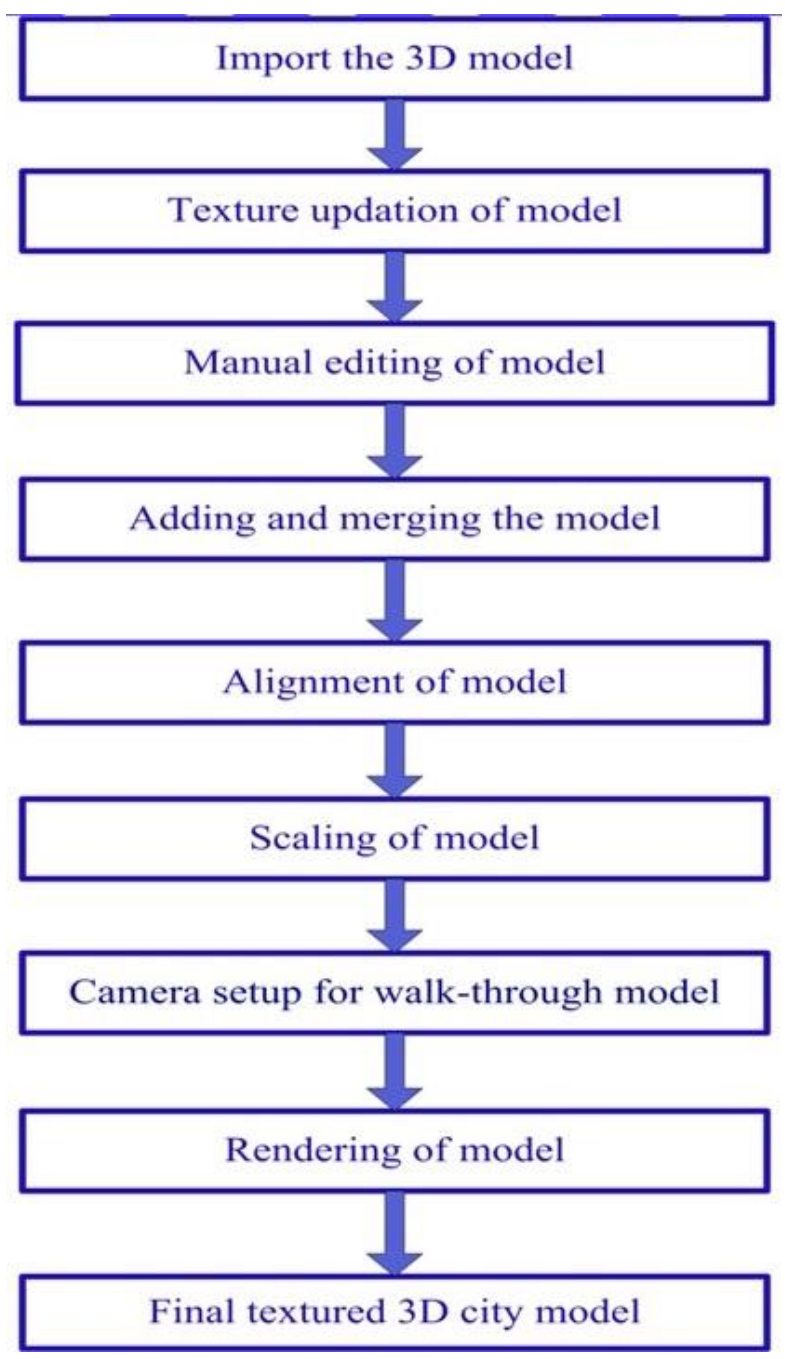

Figure 17: Flow diagram of methodology for data combination

From Agisoft Photoscan, 3D model imported to 3Ds max 2014 for further processing. Texture up-dation is also essential step.

Manual editing, adding and merging the model and alignment of model are the main step for this data combination process. After this, scaling was done for accurate 3D modeling. Now, it is complete photo-realistic, scalable 3D model of an area.

In such a way, any number of parts of a large area of city can be created.

For walk-through model creation, camera setup was used in 3 Ds max software. For further very fine resolution $3 \mathrm{D}$ model, rendering is also a important step. 


\section{Rendering of 3D model}

$3 \mathrm{D}$ rendering is the $3 \mathrm{D}$ computer graphics process. It is an automatic process to convert 3D wireframe model into $2 \mathrm{D}$ images with 3D photorealistic effects. Rendering gives a final photo-realistic look for 3D model.

In this research work, complete 3D model of civil engineering department, IIT-Roorkee, was created.

Figure 18, Figure 19 and Figure 20, are showing the 3D model of study area.

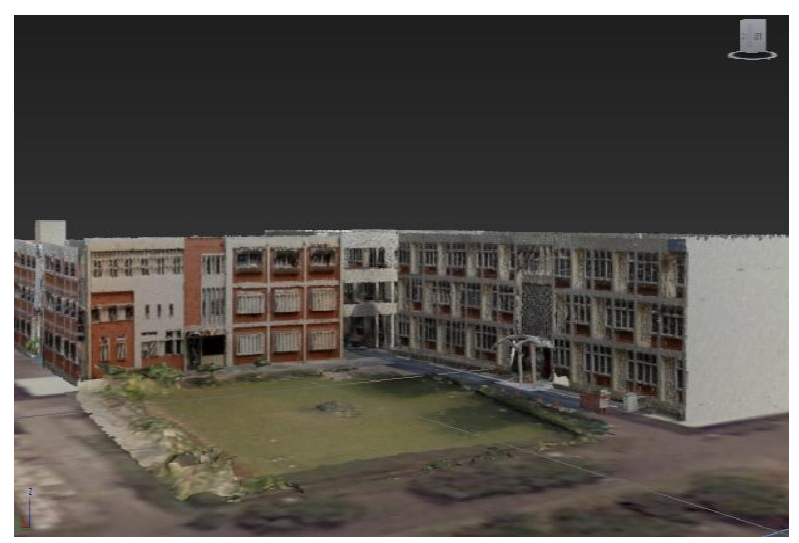

Figure 18: 3D model of civil engineering department

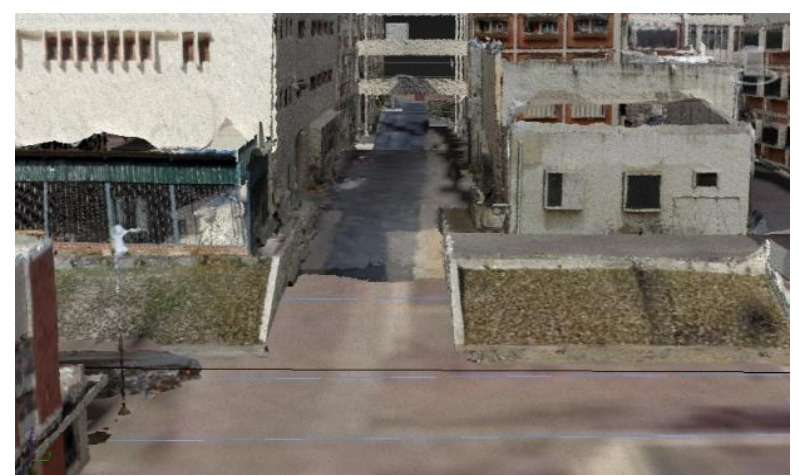

Figure 19: 3D model of civil engineering department (Another view)

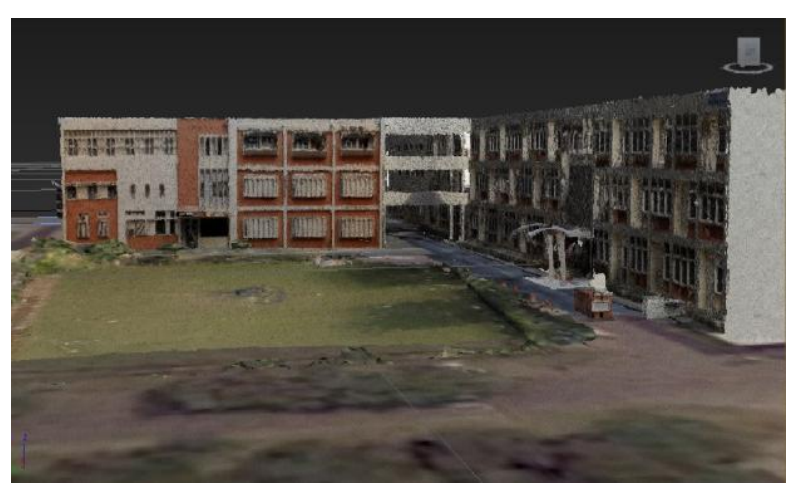

Figure 20: Another view for 3D model of civil engineering department (After rendering)

\section{SOFTWARE USED}

$>$ Video to image frame creator: for video to image frames creation.

$>$ Agisoft Photoscan Pro (0.1.1), used for 3D data processing.

$>$ 3DS Max 2014, used for data combination process.

\section{RESULT AND DISCUSSTION}

By using this proposed image based study, a photorealistic virtual 3D model created for department of civil engineering, Indian Institute of Technology, Roorkee, (IIT-R), India. As a result, textured street view of civil engineering department, IIT-Roorkee campus generated. It gives a realistic look for a model. It also covers more details of façade. The cost of project and accuracy of 3D model are much better than conventional method. The campus model acts as prototype of a city. Thus this method represent as a complete method to create virtual 3D city model. Measurement and scaling are also possible in this model.

Accuracy of model- The accuracy of model is given as below in table 1 .

Table 1: Accuracy result analysis for 3D model

\begin{tabular}{|c|c|c|c|}
\hline Building detail & $\begin{array}{l}\text { Tape } \\
\text { measure } \\
\text { ment (m) }\end{array}$ & $\begin{array}{l}\text { Model } \\
\text { measure } \\
\text { ment } \\
\text { (m) }\end{array}$ & $\begin{array}{l}\text { Difference } \\
\text { (m) }\end{array}$ \\
\hline $\begin{array}{c}\text { Civil Engg. main } \\
\text { building (Length) }\end{array}$ & 112.75 & 112.77 & 0.02 \\
\hline $\begin{array}{c}\text { Civil Engg. main } \\
\text { building (Width) }\end{array}$ & 18.10 & 18.10 & 0.00 \\
\hline $\begin{array}{c}\text { Civil Engg. main } \\
\text { building (Height) }\end{array}$ & 11.80 & 11.80 & 0.00 \\
\hline $\begin{array}{c}\text { Bridge (Length) } \\
\text { Bridge (Width) }\end{array}$ & 13.10 & 13.10 & 0.00 \\
\hline $\begin{array}{c}\text { Transportation } \\
\text { building (Length) }\end{array}$ & 41.00 & 41.00 & 0.00 \\
\hline $\begin{array}{c}\text { Transportation } \\
\text { building (Width) }\end{array}$ & 14.25 & 14.25 & 0.00 \\
\hline $\begin{array}{c}\text { Transportation } \\
\text { building (Height) }\end{array}$ & 11.50 & 11.50 & 0.00 \\
\hline $\begin{array}{c}\text { Lawn area } \\
\text { (Length) }\end{array}$ & 42.20 & 42.21 & 0.01 \\
\hline $\begin{array}{c}\text { Lawn area } \\
\text { (Width) }\end{array}$ & 39.60 & 39.61 & 0.01 \\
\hline
\end{tabular}

Accuracy of this model is mainly depends on the scaling of model. The dimensions of building are measured by physical method and enter into model by using scaling method. Thus the output accuracy of model is much better and near to accurate value. In this case, all distances are measured by using Tape. In all the cases, the distances match with the field measurement and model measurement. There is a small variation in the actual measured value and model value due to the inaccurate measurement or mistake during scaling. Thus this 3D model is accurate within the acceptable limit. This implies that the developed model is much suitable for 3D city modeling. 
Advantages and limitations of this method are also discussed. Following are the main advantages and limitation of this method;

\section{Advantages}

The main advantages of this method are as given below:

1. Video recording is simple and fast method for data collection of a large area.

2. Camera calibration is not essential step.

3. More details are possible due to high resolution camera.

4. Useful for municipality to find encroachment of area.

5. Suitable for any size of city (from small size city to metro city).

6. Suitable for 3D city navigation.

7. Useful for 3D city tourism.

8. Mostly processing steps are automatic, so it reduces the time and cost of project.

9. Texture quality is good.

10. Accuracy of $3 \mathrm{D}$ model is also near to actual value.

\section{Limitations}

This method also has following limitations.

1. Cropped or modified images will not acceptable.

2. Automatic processing needs the high level configuration of computer.

3. It needs high RAM and high computer graphic card.

4. Its accuracy depends on external dimension measurements.

5. This method is not suitable for crowd city area, because modified images are not allowed.

6. Adding and merging of parts of 3D model is required. Texture up-dation is also essential.

\section{CONCLUSION}

The summary of this study summarized as given below:

This research study gives a solution to create 3D city model by using image based approach. Video recording is a very cost effective solution for image data acquisition of a large city area. Image frames were created from video data for 3D processing. At the end, 3D product created. It is photorealistic, textured, scalable 3D model of an area. Thus it is a complete methodology to create 3D city model.

The measurement is also possible in this method. Measured dimensional value entered by using scaling method. Thus accuracy of model depends on input value. In this study, the accuracy of 3D model is within acceptable limit. The textured quality is also good and depends on camera resolution. Higher resolution gives better texture. After 3D rendering process, it gives a photo-realistic look.

This photogrammetric method is much better and most of the processing steps are automatic. This method has more advantages than any previous method available for image based 3D city modeling. This method also has very few limitations also.

The main aim of this research paper is, to provide a simple and cost effective photogrammetric method for 3D modeling user community. This study is based on a small area like campus of any educational institute. 3D model of any educational institute is acts as a prototype of a large city. Thus this method is suitable for 3D modeling of a city. This method is also useful for various kind of applications such as; municipality for encroachment identification, architecture community, 3D navigation, film and 3D game industry etc.

\section{ACKNOWLEDGMENT}

This work was supported by the MHRD grant (also called as Institute Fellowship; duration from Jan.-2009 to Dec.-2012) given by Indian Institute of Technology, Roorkee, Uttarakhand, India. Also thanks to my friends and staff of Civil Engineering Department of IIT-Roorkee for support us during this work.

\section{REFERENCES}

Anuar Ahmad, Lawali Rabiu, 2011, "Generation of three dimensional model of building using photogrammetric technique", IEEE, 7th International Colloquium on Signal Processing and its Applications.

Barber D, Mills J, Bryan PG, 2001, "Laser Scanning and Photogrammetry: 21 st century metrology", In: Proceedings of 18th International Symposium CIPA 2001, Potsdam, Germany, September $18-21$, pp $360-366$.

C. Armenakis and Gunho Sohn, 2009, "i Campus: 3D modeling of York University campus", ASPRS 2009 Annual Conference, Baltimore, Maryland, March 9-13.

Francesco Nex and Fulvio Rinaudo , 2011, "LiDAR or Photogrammetry? Integration is the answer", Italian Journal of Remote Sensing, 43 (2), pp. 107-121.

Fabio Remondino, Francesco Nex, Luigi Barazzetti, Marco Scaioni, Daniele Sarazzi, 2013, "UAV photogrammetry for mapping and 3D modeling - current status and future perspectives",

Fabio Remondino, and Sabry El-Hakim., 2006, "Image based 3D modelling: A Review", The Photogrammetric Record, 21, 115, 269-291.

Goel Salil, Yadav Manohar, Singh Anjani K., and Lohani Bharat, 2013, "An indigenous development of land based mobile mapping system", India Geospatial Forum, Hyderabad, 22-24, January.

Haala, N.; Kada, M., 2010, "An update on automatic 3D building reconstruction", ISPRS J. Photogrammetry and Remote Sensing, 65, 570-580.

Hosseininaveh, A., Robson, S., Boehm, J., Shortis, M., \& Wenzel, K. 2013, “A comparison of dense matching algorithms for scaled surface reconstruction using stereo camera rigs", ISPRS Journal of Photogrammetry and Remote Sensing. 
Luhmann Thomas, and Tecklenburg Werner, 2004, "3D object reconstruction from multiple-station panorama imagery", International Archives of the Photogrammetry, Remote Sensing and Spatial Information Sciences 34, No. 5/W16: 8

Luhmann Thomas, Robson Stuart, Kyle Stephen , Harley Ian , 2011, "Close Range Photogrammetry: Principles, Techniques and Applications", (Book), Publisher: Whittles Publishing; ISBN-13: 978-1849950572.

Noah Snavely, Steven M. Seitz, Richard Szeliski, 2006, "Photo tourism: Exploring photo collections in 3D," ACM Transactions on Graphics (SIGGRAPH Proceedings), 25(3), 835-846.

Pottler, K., Lüpfert, E., Johnston, G. H. and Shortis, M. R., 2005, "Photogrammetry: A powerful tool for geometric analysis of solar concentrators and their components", Journal of Solar Energy Engineering, 127(1): 94-101.

Richard Hartley, 1992, "Estimation of relative camera positions for uncalibrated cameras", Proceedings of European Conference on Computer Vision.

Richard Hartley and Andrew Zisserman, 2003, "Multiple view geometry in computer vision", Cambridge University Press, ISBN 0-521-54051-8.

Robson, S. and Shortis, M. R., 2007, Engineering and Manufacturing. In: Applications of 3D measurement from images, J. G. Fryer, H. Mitchell and J. A. Chandler (Editors). Whittles Publishing, Caithness, U.K. ISBN 978-1870325-691. 384 pages.

Robson, S., Boehm, J., Shortis, M., \& Ahmadabadian,, A. H. 2013, "Image selection in photogrammetric multi-view stereo methods for metric and complete 3D reconstruction", Proceedings of SPIE - The International Society for Optical Engineering, 8791. doi:10.1117/12.2020472

Singh, Surendra Pal, Mandla, V. Ravibabu, Jain, Kamal, 2012, "3D building modeling from Close Range Photogrammetry", International conference in Geomatrix-12, Feb 26-29, CSRE, Indian Institute of Technology-Bombay, India.

Singh, Surendra Pal, Jain, Kamal, Mandla, V. Ravibabu, 2013 a, "Design and calibration of multi camera setup for 3D city modeling", International Journal of Engineering Research \& Technology (IJERT), Vol. 2, Issue 5, May.

Singh, Surendra Pal, Jain, Kamal, Mandla, V. Ravibabu, 2013 b, "Image based 3D modeling of campus (Department of Civil Engineering, IIT Roorkee, Uttarakhand, India) by using SketchUp", International Journal of Advanced Civil Engineering and Architecture Research, September, Volume 2, Issue 1, pp. 65-71, Article ID Tech-168.

Singh, Surendra Pal, Jain, Kamal, Mandla, V. Ravibabu, 2013 c, "Virtual 3D city modeling : Techniques and applications", International Archives of the Photogrammetry, Remote Sensing and Spatial Information Sciences, Volume XL-2/W2, ISPRS 8th 3DGeoInfo Conference \& WG II/2 Workshop, 27 - 29 November, Istanbul, Turkey.
Singh, Surendra Pal, Jain, Kamal, Mandla, V. Ravibabu, 2013 d, "Virtual 3D campus modeling by using Close Range Photogrammetry", American Journal of Civil Engineering and Architecture, Vol.1, No.6, Page-200-205. December, doi: 10.12691/ajcea-1-6-9.

Singh, Surendra Pal, Jain, Kamal, Mandla, V. Ravibabu, 2014 a, "3D scene reconstruction from video camera for virtual 3D city modeling", American Journal of Engineering Research (AJER), Volume-03, Issue-01, January, pp-140148.

Singh, Surendra Pal, Jain, Kamal, Mandla, V. Ravibabu, 2014 b, "Image based virtual 3D campus modeling by using CityEngine", American Journal of Engineering Science and Technology Research,Vol.2,No.1, January 2014, PP: 01-10, ISSN: 2327-8269 (Online)

Shashi M. and Jain Kamal, 2007,

"Use of Photogrammetry in 3D modeling and visualization of buildings", Asian Research Publishing Network (ARPN) Journal of Engineering and Applied Sciences, Vol. 2, No. 2, April, ISSN 1819-6608.

Shortis, M. R. and Beyer, H. A., 2001, "Sensor technology for close range photogrammetry and machine vision", In: Close Range Photogrammetry and Machine Vision, K. B. Atkinson (Editor), 2nd Edition. Whittles Publishing, Caithness, U.K. ISBN 978-1870325-73-8, 371 pages.

Shortis, M. R., Harvey, E. S. and Abdo, D. A., 2009, "A review of underwater stereo-image measurement for marine biology and ecology applications", In Oceanography and Marine Biology: An Annual Review, Volume 47, Gibson, R. N., Atkinson, R. J. A. and Gordon, J. D. M. (Editors), CRC Press, Boca Raton FL, USA, ISBN 978-1-4200-9421-3, 342 pages.

Zlatanova S., Paintsil J., Tempfli K., 1998, "3D object reconstruction from aerial stereo images", In Proceeding of the 6th international conference in Central Europe on computer graphics and visualization, Vol. 98, 472-478.

Zulkepli Majid, Halim Setan, Mohamad Ghazali Hashim, and Julian Goh, "3D campus modeling using terrestrial laser scanning technology -First experience in Malaysia", 3D Geoinfo 2008, Seoul, KOREA, 13-14 November 2008.

\section{Web-references:}

1. http://agisoft.ru/products/photoscan/professional (Accessed date 20/12/2013)

2. http://www.autodesk.com/education/freesoftware/3ds-max (Accessed date 20/01/2014) 